\title{
Adaptive Travel Behaviors to Cope with COVID-19: A Swedish Qualitative Study Focusing on Everyday Leisure Trips
}

\author{
Emma Strömblad ${ }^{1,2, *(\mathbb{D})}$, Lena Winslott Hiselius ${ }^{1,2} \mathbb{(}$, Lena Smidfelt Rosqvist ${ }^{3} \mathbb{D}$ and Helena Svensson ${ }^{1,2}$ \\ 1 Department of Technology and Society, Lund University, SE-221 00 Lund, Sweden; \\ lena.hiselius@tft.lth.se (L.W.H.); helena.svensson@tft.lth.se (H.S.) \\ 2 K2-The Swedish Knowledge Centre for Public Transport, Bruksgatan 8, SE-222 36 Lund, Sweden \\ 3 Trivector Traffic, Vävaregatan 21, SE-222 36 Lund, Sweden; lena.smidfelt@trivector.se \\ * Correspondence: emma.stromblad@tft.lth.se
}

Citation: Strömblad, E.; Winslott Hiselius, L.; Smidfelt Rosqvist, L.; Svensson, H. Adaptive Travel Behaviors to Cope with COVID-19: A Swedish Qualitative Study Focusing on Everyday Leisure Trips. Sustainability 2021, 13, 12979. https:// doi.org/10.3390/su132312979

Academic Editor: Armando Cartenì

Received: 29 September 2021 Accepted: 18 November 2021 Published: 23 November 2021

Publisher's Note: MDPI stays neutral with regard to jurisdictional claims in published maps and institutional affiliations.

Copyright: (c) 2021 by the authors. Licensee MDPI, Basel, Switzerland. This article is an open access article distributed under the terms and conditions of the Creative Commons Attribution (CC BY) license (https:// creativecommons.org/licenses/by/ $4.0 /)$.

\begin{abstract}
The COVID-19 pandemic has caused a rapid change in travel behavior for different types of trips, including everyday social and recreational leisure trips. People have used adaptive travel behaviors to cope with the new circumstances for activities and transport. Due to the Swedish strategy focusing on more voluntary restrictions, people have had reason to consider which trips and activities to skip and which to keep. The overall aim of the study is to explore and deepen the knowledge about adaptive behaviors used and seek to understand its possible implications for future travel behavior change towards sustainable mobility through the use of qualitative interviews focusing on everyday leisure trips. The results illustrate how people have used a range of adaptive behaviors to cope with the implications of the pandemic, with cancellation and change of transport mode being the ones most reflected upon by the interviewees. Further, the results reveal how the overall label "everyday leisure trips" in fact includes a variety of trip purposes that differ in terms of flexibility and importance and must thus be approached in different ways in transport policy measures.
\end{abstract}

Keywords: COVID-19; disruptive events; adaptive travel behavior; everyday leisure travel; social and recreational trips; sustainable transport

\section{Introduction}

The COVID-19 pandemic, as an unplanned disruptive event, has forced rapid and changing adaptations to the new circumstances that it brought about. Governments, authorities, companies, and individuals all over the world have responded by trying to find strategies for how to handle the new roadmap for activities and transport. Conditions have varied greatly between countries, ranging from more voluntary recommendations in, for example, Sweden, to total lockdowns in many other countries [1]. Individuals have responded to the varying conditions by changing travel behavior for different trip purposes, including everyday leisure trips for social and recreational purposes. Such trips account for as much as a third of the total distances travelled by car $[2,3]$.

Previous studies have demonstrated how people use a variety of adaptive travel behaviors in the case of planned or unplanned disruptive events (e.g., [4-6]). Such behavioral adaptations range from total cancellation to adaptations that enable people to still partake in the planned activities in some way, e.g., using a different transport mode, travelling at another time, or changing the destination. In the case of COVID-19, numerous studies have shown a substantial decrease in the overall number of trips and that change of transport mode is a commonly used adaptive behavior, particularly changing from public transport to other transport modes (e.g., [7-10]). This change is presumably to do with both restrictions and with a fear of being infected due to the close proximity among passengers in public transport. However, even though there is a vast body of literature on the subject, it is not yet clear how COVID-19 is transmitted in public transport and if travelling by public transport increases the risk of infection $[11,12]$. Some studies cannot prove a correlation 
between public transport use and transmission rate/case incidence/mortality (e.g., [13,14]), while others do show such a correlation (e.g., $[15,16])$.

Even though the Swedish strategy for managing the pandemic has mainly been based on recommendations, adaptations to travel behavior have also taken place in Sweden. For example, analyses by Jenelius and Cebecauer [13] show that the decrease in trips with public transport was substantial (40-60 percent across regions in Sweden) and severe compared with other transport modes. Winslott Hiselius and Arnfalk [17] focused on trips to work and business trips in Swedish public agencies and showed that 86 percent of the respondents changed their commuting trips and only 3 percent of those who made business trips before continued to do so during the pandemic. Interestingly, Bohman et al. [18] presented results specifically for social and recreational trips, showing that common adaptive behaviors were a decrease in the frequency of activities and associated travel, modal adjustment, and a shift to the outdoors.

Travel behavior changes are also needed to help reduce greenhouse gas emissions from transport and achieve a sustainable transport system. Some have pointed out the need to pay attention to possible implications of changed travel behavior during the pandemic, particularly the risk of long-term effects of the current shift from public transport to an increasing car dependence (e.g., $[19,20])$. Others have discussed the possibility to take advantage of the current situation when finding ways to transition to more sustainable travel behavior (e.g., [20-24]). Results presented above indicate that people have been able to make rapid behavioral changes for a variety of activities and have been using a number of adaptive strategies when travelling the usual way was no longer eligible. However, to learn from these experiences, there is a need for a deeper understanding about how people perceive the changes they have made during the pandemic. This will in turn give an idea of whether these behavioral changes will give long-term effects or not, and also what is needed to keep sustainable changes.

Due to the voluntary approach used in Sweden, it is particularly interesting to study how its inhabitants have perceived their travel behavior changes during the pandemic, since they have had reason to consider which trips and activities to skip and which to keep. One such attempt has been made by Bohman et al. [18], who employed qualitative data embedded in a quantitative study design to obtain an understanding of how people perceive their changes in travel behavior. The authors illustrated how the changes were sometimes a result of having chosen to stop participating in activities and sometimes a result of having no option since the activities had been cancelled. However, qualitative studies of the effects on travel behavior of COVID-19 are so far rare, and more research is needed to obtain a deepened understanding of how people perceive their changes, since it provides important lessons in relation to the needed transition to more sustainable transport and mobility. In this context, focusing specifically on everyday leisure trips for social and recreational purposes are of special interest since they are often seen as nonmandatory, and that individuals therefore have greater control of, for example, the timing of these trips compared to mandatory trips [25]. However, such literature is also rare.

To address these research gaps, the overall aim of this interview study is to increase knowledge about adaptive travel behaviors used for everyday leisure purposes during the COVID-19 outbreak and to seek to understand its possible implications for future travel behavior change. First, we explore and deepen the picture of the adaptive behaviors people have used, and how the use of such strategies has changed travel behavior. Second, we describe how people reason about and perceive their changes, and if they believe their adaptations will last into the future or not. The analysis of adaptive behaviors is based on a categorization of behavioral adaptations to disruptive events suggested by Marsden et al. [4]. Further, the qualitative study design employed, focusing on the interpretation of the material rather than quantifying the effects of the pandemic, allows a deeper understanding of how people perceive their changes, and in particular to comprehend whether there will be long-term effects on travel behavior after the pandemic. Fulfilling the research aim described above, the results of the study will contribute to the international literature 
by using a qualitative method to analyze how people perceive their adaptive behaviors used in a context where they were urged, but not completely forced, to make such adaptations. While the analysis is retrieved for an average city in Sweden, the results should also be of relevance for other similar cities, both in Sweden and in other countries, when seeking effective policy measures to accelerate the transition to more sustainable leisure travel.

This article consists of seven main sections. After this introduction follows Section 2 with a description on previous research about disruptive events in general, as well as COVID-19 in particular. The conditions for the study are described in Section 3, and the method used in Section 4. In Section 5, the results of the studied themes in the qualitative analysis are presented, and finally, in Sections 6 and 7, results are discussed, and conclusions are presented.

\section{Previous Research}

\subsection{Adaptive Travel Behavior at Disruptive Events}

Numerous planned or unplanned disruptive events in transport have caused travel behavior changes in the past [26]. Planned disruptive events include road or rail closure due to construction or maintenance work and planned mega-events such as major sports, political meetings, or religious gatherings. For example, a study by Parkes et al. [27] of the 2012 London Olympics revealed that more than half of the commuters made at least one change, with a reduction of trips and making trips at another time as the most likely adaptations made. The COVID-19 pandemic, on the other hand, is an unplanned disruptive event similar to natural disasters, extreme weather events, transit trade union strikes, and terrorist attacks. The effects of unplanned disruptive events on travel behavior have been described in several studies (e.g., [28-30]). One such example is a study by van Exel and Rietveld [31], who made a review of 13 strikes in the public transport sector. Their results show that, on average, 10-20 percent of the trips were cancelled, and that most travelers switched to the car when public transport was no longer an option.

Even though pandemics are rare in modern history, some have studied the effects of epidemics prior to the outbreak of COVID-19. The severe acute respiratory syndrome (SARS) in 2003 resulted in a 50 percent decrease in daily ridership for the underground transit system in Taiwan during the peak of the epidemic [23]. In addition, a survey by Sadique et al. [32] revealed that 75 percent of respondents in the five European and three Asian regions that had been affected by SARS reported that they would avoid public transportation in response to a hypothetical influenza pandemic. During the outbreak of the Middle East respiratory syndrome (MERS) in 2015, public transport use in Seoul in South Korea decreased by 12 percent when fear of the infection peaked [33]. In addition, in a study of the Ebola outbreak in Sierra Leone in 2015 by Peak et al. [34], analyses of cell phone data showed a substantial decrease in human mobility during a three-day lockdown.

\subsection{Classification of Adaptive Travel Behaviors}

When disruptive events occur, people have to adapt to the new conditions. Such adaptive behaviors include a change of transport mode, taking a different route than normal, travelling to a new destination, postponing the trip to another start time, etc. Different attempts have been made to classify these behavioral adaptations into a set of adaptive behaviors. For example, van Exel and Rietveld [6] studied adaptive behaviors to a planned one-day rail strike in the Netherlands. They classified the possible behavioral reactions into four types: (1) other day, by train; (2) same day, car as driver; (3) same day, other mode (including car as passenger); (4) abandon trip. During the 2012 London Olympics, interventions of the organizers focused in particular on four types of changes: reducing, retiming, rerouting, or remoding journeys, where reducing included working from home, working elsewhere, or taking annual leave [27]. Further, Marsden et al. [4] expanded this categorization into a total of seven behavioral adaptations by adding another three categories: rescheduling, relocating, and reallocating (passing over the responsibility for a journey to someone else), of which rescheduling complies with type (1) in the catego- 
rization by van Exel and Rietveld [6]. The addition was the result of analyses by Marsden et al. [4], based on a baseline everyday survey and three responsive mixed methods surveys. These three case studies all investigated changes in traveler behavior due to disruption in the UK and consisted respectively of a major snow and ice weather event in 2013, a major flooding event in 2014, and the closure of a major estuarial road crossing in 2015. The Marsden classification is used as an analytical framework in this article, as described in Section 4.4. Several of the strategies in this classification can have a positive impact in terms of contributing to the creation of sustainable mobility [4]. Besides the commonly used strategy remoding, other strategies that can potentially contribute to less travel and lower emissions are relocating, reducing, and reallocating.

\subsection{Travel Behavior Effects of COVID-19}

Nearly all sorts of trips have been affected by the COVID-19 outbreak. The overall number of trips and kilometers travelled were drastically reduced during the initial phase of the pandemic (e.g., $[8,10,35])$. Trips to work and school have decreased due to a large increase in the number of employees working or studying from home (e.g., $[17,36])$. Further, trips for social and recreational purposes have also been reduced (e.g., [10,36]). However, one type of recreational trip that seems to have increased during the pandemic is trips to parks [37].

Besides reductions in the number of trips, remoding is an adaptive behavior that has been widely used during COVID-19. Numerous studies around the world have demonstrated a decrease in public transport use in the favor of private car (e.g., $[9,35,38]$ ) and active transport modes such as cycling (e.g., [8]) and walking (e.g., [10]). According to Eisenmann et al. [39], only 13 percent of the adult population in Germany used public transport during the lockdown compared to 23 percent before the pandemic.

\subsection{Long-Term Effects on Travel Behavior}

Several studies also report on long-term effects due to disruptive events. Follow-ups of previous epidemics have shown that travel behavior returned to normal levels about three months after the peak of the SARS epidemic in Taiwan [23] and within days after restrictions were lifted from a three-day national lockdown during the Ebola outbreak in Sierra Leone [34]. A follow-up of travel and activities during the early days of easing restrictions after the COVID-19 outbreak in Australia showed that there was a strong bounce back in travel by car and that travel by active transport modes had returned to prepandemic levels about two months after the lockdown peak [9]. Regarding trip purposes, general shopping had increased, whereas commuting and business trips remained relatively flat. For nonwork trips, the effect was greater and, in terms of household plans for the upcoming week, such trips were more than returning to normal.

Further, respondents in studies by König and Dreßler [40] and de Haas et al. [10] expected the long-term effects of the current situation on future transport mode choices to be weak, but with higher agreement on statements about continuing to use the bike and walking by foot more often, and lower agreement about going by car more often and public transport less often than before the pandemic. The study by König and Dreßler [40] also showed that there was higher agreement on statements about remoding than about being less mobile in general in the coming months and years. A study by Bin et al. [41] investigated how individuals have changed their activity travel pattern and internet usage during the first wave of COVID-19, and which of these changes may be kept. Their results indicate that long-term effects on the use of online alternatives are correlated to personality and sociodemographic group.

\section{Scope of the Study}

3.1. Geographical Area

The interview study presented in this article was conducted among residents of Gävle, a medium-sized town which fairly well represents an average city in Sweden. For example, 
Gävle has a population similar to the average for Sweden in terms of gender and age distribution [42], level of educational attainment [43], and car ownership per thousand inhabitants [44]. A large proportion of the housing in Gävle is located within a radius of 5 kilometers from the city center. The city has a developed network for bicycle traffic [45], and therefore no explicit policy measures to improve bicycle infrastructure by, for example, introducing temporary pop-up bicycle lanes were taken in Gävle due to the pandemic. Finally, public transport services in Gävle include both long-distance and regional trains, regional buses, and a city bus network [46].

Travel survey data reveals that trips for social and recreational purposes account for over a quarter of the total number of trips made by inhabitants of Gävle municipality based on data collected using a smart phone app [47]. Further, private car is the dominant transport mode, used for about 60 percent of social trips to visit family and friends and about 40 percent of recreational trips for exercise and outdoor life and entertainment and culture. The public transport share is just over 5 percent, the bicycle share about 10 percent, and trips by foot account for about 35 percent.

\subsection{Time Period}

Where many of the initial studies of COVID-19 effects on travel behavior focus on the very early stages of the pandemic (e.g., $[10,13,36])$, the interviews of this study were conducted in November 2020, about eight months into the pandemic. As in many European countries, the coronavirus started to spread in Sweden in the spring of 2020. The number of confirmed cases increased rapidly in the beginning of March and stayed at a high level until the end of April, after which there was a decline. During the summer and beginning of autumn, from June to October, the spread was at a lower level. In November and at the time of the interviews, however, there was a quick increase in the number of new cases as the second wave of the pandemic took off [48]. At this time, the Public Health Agency of Sweden decided on stricter recommendations for counties with a high spread of the infection. In Gävle, the new recommendations came into force in mid-November 2020 and included advice to avoid physical contact with anyone other than persons in the own household, to refrain from going to indoor environments and from meetings with larger groups of people, and also to avoid unnecessary travel [49].

\subsection{Type of Errands}

This study focused on everyday leisure trips for social and recreational purposes, thus excluding holiday trips. The scope was also limited to leisure trips without a sleepover. The interviewees were told that focus was on leisure trips that can be done during the day, and not on longer weekend or holiday trips. Our definition of leisure trips included, but was not limited to, visiting family and friends, going to restaurants and cafés, entertainment and culture, outdoor activities, exercise/training/sports, other hobbies or club activities, shopping for fun, and participating in or accompanying children in their leisure activities. In the literature, such nonmandatory activities are sometimes referred to as discretionary and separated from nonmandatory maintenance activities such as shopping and service trips [25]. This type of trips has previously been proven harder to affect than trips associated with basic needs or compulsion [50,51].

\section{Materials and Methods}

\subsection{Recruitment and Participants}

The participants of the study were recruited among residents of Gävle municipality aged 18 years and above, with the help of a recruitment firm. Starting from a random sample from an address register of the whole population, people were contacted by phone, and screening questions were asked to ensure capturing participants with different characteristics (see Table 1). Since our goal was to cover as many aspects as possible by interviewing a wide variety of individuals, the final sample was not fully randomized, and neither was the nonresponse. Those who chose to participate were offered a gift card of SEK 400. In 
total, 17 interviews were conducted, after which thematic saturation was reached, meaning the most recent interviews did not add any new aspects within the researched area [52,53]. More information about the sociodemographic background of the interviewees and their access to various transport modes is presented in Appendix A.

Table 1. Background information of the interviewees.

\begin{tabular}{cccccc}
\hline Participant & Gender & Age Group & $\begin{array}{c}\text { Children in } \\
\text { Family }\end{array}$ & Residence & Car Access \\
\hline P01 & Female & $18-24$ & Siblings & Gävle & Gets a ride \\
P02 & Male & $25-44$ & No children & Other urban & 1 car \\
P03 & Female & $18-24$ & Siblings & Gävle & 1 car \\
P04 & Female & $25-44$ & No children & Gävle & Shares a car \\
P05 & Female & $25-44$ & 7-18 years & Gävle & 2 cars \\
P06 & Female & $45-64$ & Grandchildren & Rural & 1 car \\
P07 & Female & $18-24$ & No children & Gävle & Gets a ride \\
P08 & Female & $45-64$ & No children & Other urban & Not now \\
P09 & Male & $18-24$ & Siblings & Gävle & 1 car \\
P10 & Male & $45-64$ & No children & Gävle & 1 car \\
P11 & Male & $25-44$ & No children & Gävle & 1 car \\
P12 & Male & $45-64$ & No children & Gävle & 1 car \\
P13 & Male & $25-44$ & $0-6$ and 7-18 years & Gävle & Not now \\
P14 & Male & $45-64$ & 7-18 years & Rural & 2 cars \\
P15 & Male & $45-64$ & Grandchildren & Gävle & 2 cars \\
P16 & Male & $25-44$ & $0-6$ and 7-18 years & Other urban & 2 cars \\
P17 & Female & $45-64$ & 7-18 years & Other urban & 2 cars \\
\hline
\end{tabular}

\subsection{Interview Procedure}

The interviews followed a semi-structured interview guide with open-ended questions. The questions covered two themes (see Figure 1): if and how the pandemic has affected trips for everyday leisure purposes (aim 1), and how the interviewees have perceived their changes and if they will stick to them after life is back to normal again (aim 2). The interview guide was applied loosely, and follow-up questions were adapted to explore particularly interesting statements made during the interviews. The respondents were able to talk freely around everyday leisure trips. However, to facilitate a focus on the types of leisure trips of this study, as described in Section 3.3, the interviewees were given a definition during the interview.

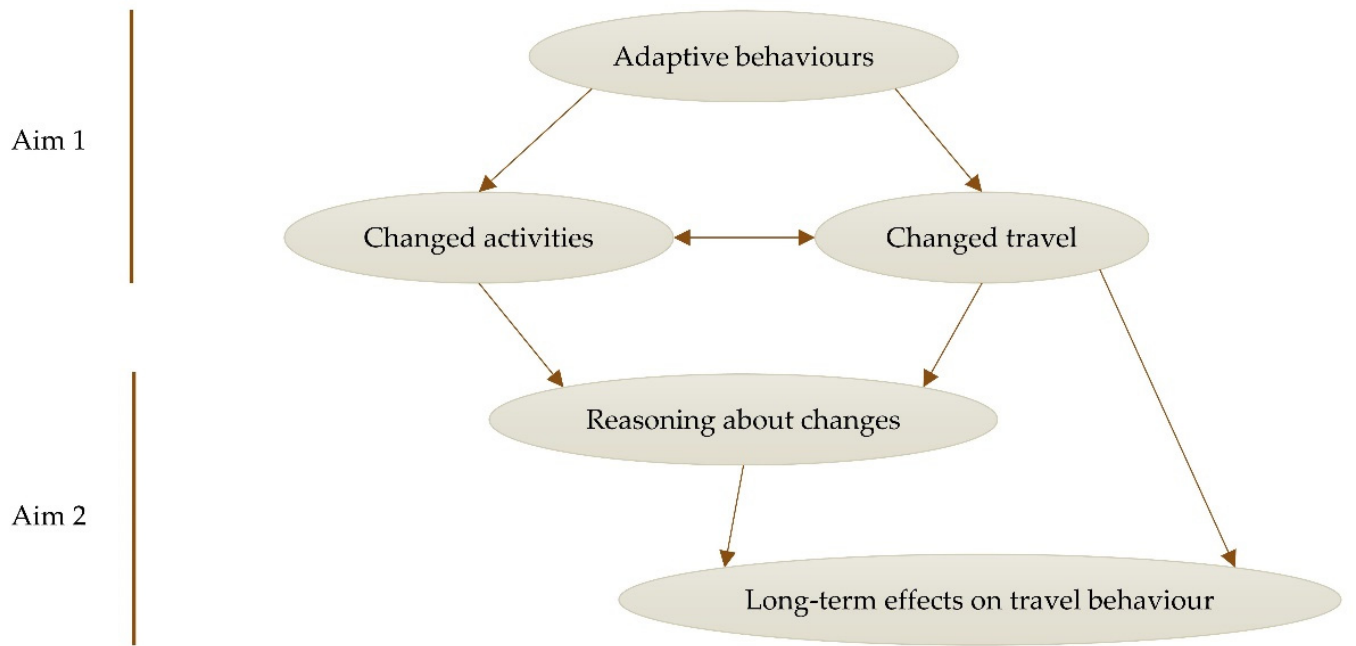

Figure 1. Themes in the interview guide and how they relate to the aims of the study. 
As mentioned earlier, the interviews took place in November 2020. Each interview lasted for about 45-60 min. Due to COVID-19, the interviews took place online. The video meetings were recorded to enable transcribing the interviews in detail afterwards. Before the interviews, all respondents consented to participating in the research study, to the interviews being recorded, and to storing data according to General Data Protection Regulation (GDPR). A challenge when conducting the interviews was that the spread of COVID-19 was rather low at the start of the interview period but then increased quickly during the interview month. However, the questions asked related to COVID-19 remained the same in all interviews.

\subsection{Transcribing, Coding, and Data Analysis}

The interviews were transcribed verbatim, based on sound recordings of the video meetings. Inductive qualitative thematic analysis was conducted as described by Braun and Clarke [54]. After transcription, all texts were read and reread, after which initial codes were generated. The transcripts were then coded in a systematic way according to the initial codes, and thus a data-driven approach was used. The next step was to focus on the broader level of data and organize the different codes into themes based on the analytic framework. Further analysis resulted in an identification of a number of sub-themes. Finally, the sorting of text segments into codes, codes into sub-themes, and sub-themes into themes were reviewed several times in an iterative process until a final satisfactory match was achieved.

\subsection{Analytical Framework}

The analytical framework used in this study is based on the categorization of behavioral adaptations to disruptive events (seven in total) suggested by Marsden et al. [4], as described in Section 2.2. Five of the behavioral adaptations constitute themes in the analysis: remoding, retiming, rescheduling, relocating, and reducing (not conducting a trip at all but doing the activity through ICT instead, e.g., meeting friends online or watching sports on TV instead of at the arena). In this categorization, retiming refers to modifying the time at which a trip starts, while rescheduling means changing when in the week a trip is made. Behavioral adaptions categorized as rerouting or reallocating were not mentioned by the interviewees and are hence not themes in the analysis. In Marsden et al. [4], cancellation of a trip was not included, with the motivation that it is not a policy strategy but an emergency response. However, in the COVID-19 situation, people have had to prioritize which trips to make and which trips to cancel, which makes this strategy more than an emergency response. Cancellation is therefore added as one of the themes in the analysis.

\section{Results}

\subsection{Use of Adaptive Behaviors}

The COVID-19 pandemic has affected trips to leisure activities for all of the interviewees. Some perceived that they made big changes, especially in terms of cancelling trips and activities. Others at first perceived their changes to be fairly small, and that life continued pretty much as before the pandemic. However, follow-up questions during the course of the qualitative interviews revealed that most of the interviewees had made quite some changes.

The interviewees used a number of adaptive behaviors to cope with the effects of the pandemic: cancellation, remoding, retiming, rescheduling, relocating, and reducing. These strategies constitute the six main themes of the analysis. For each theme, results are presented first for "use of adaptive behaviors" in this section and second for "reasoning about adaptive behaviors" in Section 5.2. The two subsections thus present results, respectively, for each part of the twofold aim of the study, with this first section focusing on behavioral adaptations of everyday leisure travel and Section 5.2 focusing on how the interviewees have perceived their changes and if they believe their adaptions will last into the future or 
not. Further, the presentation of the results for "use of adaptive behaviors" in this section includes a number of sub-themes, as presented in Table 2.

Table 2. List of themes for "use of adaptive behaviors".

\begin{tabular}{cc}
\hline Themes & Sub-Themes \\
\hline Cancellation & Fewer trips to meet family and friends \\
& Fewer trips to restaurants, entertainment, and shopping for fun \\
Remoding & Fewer trips for indoor training \\
& Shift from public transport to car \\
Retiming & Shift from public transport to active modes \\
& Avoiding rush hour in public transport \\
Rescheduling & Avoiding crowding at the destination \\
Relocating & Travelling on weekdays instead of weekends \\
& Doing trips downtown instead of to the mall \\
\hline
\end{tabular}

\subsubsection{Cancellation}

Due to the pandemic, the interviewees have cancelled trips to many types of everyday leisure activities. To start with, they report a big decrease in the number of trips for meetings with family and friends, especially with older relatives being vulnerable to COVID-19. People met less often and therefore made fewer trips for such social activities.

"She [his grandmother] is quite old, and I do not really dare to visit her in these times.

She is over 90." (P13)

Another kind of leisure travel mentioned having been cancelled a lot are for activities that give an added value to life, such as trips to restaurants, entertainment, and shopping for fun. This type of activities often means meeting with other people, i.e., there is a partial overlap with the previous sub-theme (fewer trips to meet family and friends). Such activities mentioned by the interviewees are going to restaurants, cafés, pubs, and clubs; cultural events; watch sporting events; going to parties with friends or festivities with colleagues; performing hobbies; doing fun activities with the children; and to go shopping for fun or do spontaneous shopping. These cancellations mean fewer trips downtown, to nearby cities, and to shopping centers. In addition, many of the interviewees mention travelling less downtown, without specifying what they would normally do there, while others describe how they combine, e.g., shopping, meeting with friends, and having a coffee when going downtown. The same goes for trips to nearby cities (e.g., the Swedish capital Stockholm and the nearby city of Uppsala), since such trips often include a combination of, e.g., shopping for fun, cultural activities, attending sports events, and going to restaurants.

"Since Easter, we have hardly been to the pub at all." (P15)

"Before, you were more inclined to go to Uppsala or Stockholm and look in shops [... ] and it feels quite out of the question now." (P05)

Fewer trips to indoor training are another commonly mentioned effect of the pandemic. For example, the interviewees mention making fewer trips to the gym and that they cannot go swimming since these facilities are closed. Most gyms, on the other hand, are not fully closed but have restrictions in the number of people that can go there at the same time. This means that some interviewees attend gym classes to a lesser extent than usual while others have chosen to entirely stop going to the gym.

\subsubsection{Remoding}

A common adaptive behavior for everyday leisure trips among the interviewees was a reduction of public transport use in favor of travelling either by car or by active transport modes such as cycling and walking. First, many of the interviewees mentioned an increased use of car due to travelling less by public transport, especially at times when buses were crowded. 
"I have not travelled by bus in [ ... ] five months, all summer I travelled by car." (P07)

People both used their own cars more, were given a ride by others, and also gave family and friends a ride so that they could avoid travelling by public transport. Some described how they only occasionally had access to a car, and that they would travel more by car if they had access to it more often.

"I would probably take the car more often if I had my very own car, especially at times when I have had to travel [by bus] when there was a lot of people." (P04)

Further, a couple of the interviewees had trouble estimating whether they had increased their car use or not. On the one hand, they had reduced their overall number of leisure trips, including car trips. On the other, it seemed to them that the share of trips taken by car had increased. This was both due to remoding from public transport to car, but also because more of the shorter trips normally done by bicycle or bus had been cancelled.

Second, both biking and walking have increased during the pandemic, according to the interviewees. They have made a switch from public transport to walking on both short and somewhat longer leisure trips; for example, one interviewee (P04) mentioned walking for $20 \mathrm{~min}$ instead of travelling by bus as she would normally do. In addition, one interviewee (P07) stated that travelling by foot and bicycle instead of taking the bus governed where she could go, since it reduced her range.

\subsubsection{Retiming and Rescheduling}

Instead of avoiding public transport altogether for everyday leisure trips, another strategy used to avoid crowding in public transport was to take a bus with either earlier or later departure time than normal. Specifically, not travelling during the afternoon peak hours was mentioned by one of the interviewees (P01).

Retiming was also an adaptive behavior used in relation to the destinations people were travelling to. In order to avoid crowding at the destination some of the interviewees chose to leave home earlier in the day, e.g., when going to shopping centers, but also for outdoor activities in popular areas.

"We have been out earlier in the day than before." (P11)

Rescheduling was another strategy used to avoid crowding at the destination. For example, a couple of the interviewees mentioned not going to shopping centers in the weekends anymore but instead taking such trips on weekdays.

\subsubsection{Relocating}

Apart from an overall decrease in shopping for fun, another strategy mentioned to avoid crowding was to go downtown instead of going to shopping centers.

"[ ... ] I ignore these big shopping centers. If I need something, I can quickly and easily walk with the stroller to the city center to shop. Usually, I can find what I need downtown anyway." (P13)

Further, the interviews illustrate how more activities are now taking place outdoors, and that this sometimes means that activities are relocated. For example, interviewees have attended new outdoor forested areas to avoid crowding where they usually go and also to achieve variety since they now do more outdoor activities than before. For example, one interviewee (P11) has switched from an outdoor forested area where he usually goes to one where he perceives there are less people. Another (P15) has taken the opportunity to discover many new outdoor forested areas together with his wife.

\subsubsection{Reducing}

Several of the interviewees mentioned using various forms of digital tools to reduce travel and instead perform leisure activities at home when it was not possible to physically attend such activities. These adaptations include watching sports on screen instead of at 
sports arenas, using online video calls to meet relatives, and using online meetings to meet with groups of friends.

\subsection{Reasoning about Adaptive Behaviors}

In order to assess possible long-term effects on travel behavior due to COVID-19, a deeper understanding of how people reason about their changes is presented in this section. The pandemic is special in the way it influences many different aspects of society. Compared to other disruptive events, the pandemic not only affects the transport network but also activities themselves. Thus, even though the main focus of the interviews was on travel behavior, they also covered changes in activities, since the two are intertwined.

\subsubsection{Cancellation}

Trips to meet family and friends have been cancelled both to avoid infecting others and help curb the spread of infection but also, especially for the younger ones, because the places where they normally meet friends are no longer open and that they have less time to meet friends due to online education. When it comes to the younger interviewees, they seem to feel socially isolated and miss social activities quite a bit. Several of them mention that meeting friends is important for their wellbeing, and that the social isolation due to COVID-19 is depressing. When it comes to the middle-aged, they refer to missing the meetings with their aged parents more than they talk about not meeting friends. For both groups there is also cancellation of meetings with family members who live at a distance.

"We chose not to meet 70 plus during the covid time, including parents-in-laws and my parents, and it felt very boring." (P05)

However, a group that sees some positive effects of the social isolation is families with children, either young children living at home or older children living nearby. They appreciate spending more time together at home, with their closest family. Even so, the interviewees did not mention cancellation of social trips as a habit they want to keep.

"I think you have a closer relationship with your immediate family, because you are a bit stranded together." (P06)

Next, people miss activities that give an added value to life, such as trips to restaurants, entertainment, and shopping for fun. Some of the interviewees were so used to not being able to do this type of activities that they actually forgot mentioning them until the interviewer asked specifically about such activities. Nevertheless, many of the interviewees mentioned how they miss doing activities that give an added value to life. They perceive not doing this type of activities to be dull, boring, and tough. They mention life without such activities being limited and grey and they miss being able to do something extra. On the contrary, a bonus of the decrease in this type of activities mentioned by several of the interviewees was to save money. However, the interviewees did not mention cancellation of such activities as a habit they want to keep in the future.

"You rarely do things that make you feel good, that give some kind of added value."

When it comes to trips to the gym, some interviewees have entirely stopped going to the gym. Several others discuss how restrictions have made it more difficult to go to the gym since opening hours have changed, there are fewer group classes, and fewer people are allowed to attend classes or enter the gym as a whole. For one interviewee (P16), the gym at his workplace was closed, and he chose not to go to another gym since this would have counteracted the purpose of closing the gym. The interviewees did not mention whether this adaptation will last or not.

"I really miss being able to go there [the bathhouse] to do my workouts." (P08)

Several of the interviewees mention a feeling of being trapped at home, especially students having their teaching online due to the pandemic. They feel that they spend too much time indoors and that they are stuck at home without time or energy to do other activities than studying. Specifically, one interviewee (P03) mentions how online education 
has made her more tired after a day of school, resulting in less energy for leisure activities. Others than the students, too, mention the feeling of being inactive and trapped at home. The same interviewee (P03) mentions that some of her friends have less time to meet due to working more than normally. Other than that, changed working conditions affecting leisure trips was not commonly reflected on in the interviews.

Even though the pandemic has caused a sense of being trapped at home for some, it has also become an opportunity for recovery that others have enjoyed. These interviewees enjoy spending more time with the family, having time to reflect on what is important in life, find it good for their mental wellbeing having fewer activities and less stress in life, enjoy not feeling forced to attend activities, and find it soothing to escape the hamster wheel. This is a habit that some of the interviewees want to keep in the future.

\subsubsection{Remoding}

Apart from conducting fewer trips than normal due to the pandemic, the reason for travelling less with public transport was twofold: to avoid the risk of becoming infected and to avoid infecting others. For example, several of the interviewees mentioned not travelling by bus in the afternoon peak hours because there was crowding on the buses. Some of the interviewees discussed the feeling of stress when travelling on a crowded bus. One of them (P04) perceived that she had no alternative to travelling by bus and thus, to some extent, continued doing so in spite of the pandemic. She mentioned that the trip itself then became more stressful. Other interviewees (P01 and P09) said that they normally, too, had feelings of discomfort due to the stress of relating to many other people on the bus, feelings that were intensified with COVID-19. The answers gave no clear indications as to whether the habit of using less public transport will last when the pandemic has ceased.

One interviewee (P12) commented that he will try to go back to his normal habits of biking more and driving the car less after things return to normal. Another interviewee (P17) expressed satisfaction about travelling less by car at the moment and will reflect more upon travel mode choice in the future. Otherwise, there were no indications as to whether the habit of using the car more would continue. However, some mentioned that walking more was good for their wellbeing, and that they would try to keep this habit after the pandemic.

\subsubsection{Retiming and Rescheduling}

Retiming of leisure trips is a habit that some of the interviewees intend to stick to. For example, one interviewee (P11) likes the benefit of doing things earlier in the day when he has more energy, and how it gives him a certain peace in the afternoon.

Rescheduling leisure activities from weekends to weekdays to avoid crowding at the destination is a strategy that was used by some of the interviewees before as well, but that was more widely adopted due to the pandemic. Whether this adaptation will last into the future or not was not mentioned.

\subsubsection{Relocating}

Relocating is another adaptive behavior that people state that they will keep, especially when it comes to doing leisure activities outdoors. Some interviewees have enjoyed discovering new outdoor forested areas and will return to several of these on more occasions. Others have not clearly stated that they are going to more outdoor forested areas. However, many of them mention doing more activities outdoors, e.g., seeing elderly parents in their gardens, meeting friends outdoors either at home or in other meeting places or having a coffee in an open-air café. Further, the interviewees mention taking more walks, conducting more trips to outdoor locations, and overall spending more time in the nature. Meeting outdoors is described as a nice habit that will probably last for a long time.

"[ ... ] fun to see new outdoor places, which you have found and will surely return to as well." (P15) 


\subsubsection{Reducing}

When it comes to using digital tools to conduct leisure activities at home instead of making trips to physically attend such activities, the interviews showed that people have created new habits of using such tools. Some of the interviewees found the digital tools to be okay alternatives, but in the long run as a complement rather than a substitute to "the real deal". Others found it boring to, for example, watch sports on screen instead of live.

"[ ... that we continue this and at the same time attend the old leisure activities. And then maybe we go live there." (P02)

\section{Discussion}

The overall aim of this study is to increase knowledge about adaptive travel behaviors used for everyday social and recreational leisure trips during the COVID-19 pandemic and to seek to understand its possible implications for future travel behavior change in the transition to more sustainable transport and mobility. First of all, the results show that the interviewees have used a range of adaptive behaviors, and all have made changes, but to varying degrees. The variety of adaptive behaviors suggests that people are able to make substantive changes in different ways when needed to, due to disruptive events, in this case the COVID-19 pandemic. This is in line with findings in the article by Marsden et al. [4], who demonstrated a greater range of behavioral adaptations of travel behavior in the case of disruptive events than usually assumed. This contradicts the dominant framing that mobility patterns are stable, and that transport is more difficult to change than other energy- and carbon-intensive sectors.

However, our diving into the reasoning about everyday leisure trips in qualitative interviews reveals how this overall label in fact includes a variety of trip purposes, which differ in terms of flexibility and importance. The activity itself, as well as transport mode, time and day, destination, and the need or desire to meet others, can be more or less fixed and be differently important to people. This also affects whether adaptive travel behaviors in the case of disruptive events will give long-term effects or not. Separating everyday leisure trips into smaller categories gives a deepened understanding of which trips and activities are replaceable and thus relevant to focus policy measures on.

Trip purposes that are less replaceable are characterized by being important to people and also fixed in some way, often in terms of destination. Such trips and activities include meeting family and friends at home and going to destinations that offer something special, e.g., concerts or sporting events, a special type of gym class, or a shop that cannot be found elsewhere. During the pandemic, the most common adaptive behavior for this kind of trips has been cancellation, however, mainly due to restrictions and not out of free choice. People rather seem to miss this type of activities quite a lot. It is therefore not surprising that this adaptive behavior, as stated in the interviews, does not seem to turn into lasting habits.

Nevertheless, similar trip purposes have shown to be more flexible even when part of the activity is important to people. The choice of activity is, in fact, often a result of wanting to do something both for social and for recreational purposes at the same time. When the meeting with others is more important than the recreational activity itself, the exact destination is sometimes less important, and it can even be of value to explore new places or things to do. This has been demonstrated during the pandemic, when people have chosen to meet in outdoor forested areas instead of meeting family and friends at home or in commercial premises, which has not been an option. In addition, not wanting to travel by bus has resulted not only in switching to other transport modes but also changing the destination of trips and replacing activities with other, similar activities.

In general, there are many mentions of missing certain activities, but fewer of missing the trips themselves. New experiences of doing similar activities but in different ways has, in some cases, been perceived as positive, and something that people will hold on to. Such adaptations include remoding, retiming, rescheduling, relocating, and reducing. Perceived long-term effects on mobility behaviors were also assessed in studies by König and Dreßler [40] and de Haas et al. [10]. Overall, the respondents in these studies expected 
the long-term effects of the current situation on future transport mode choices to be weak, but with higher agreement on statements about continuing to use the bike and walk more often, and lower agreement about going by car more often and public transport less often than before the pandemic.

Further, cancellation has, in fact, also been suggested as a habit to keep. Some mention taking fewer trips in the future, since the pandemic has made them realize that it is good for them to live a less stressful life. Others talk of not taking "unnecessary" trips. This is most probably an effect of recommendations about avoiding such trips to help reduce the spread of infection. However, the reasoning about "unnecessary" trips in some cases extended to reflecting more upon which trips to make in the future in the light of sustainability problems: how often, how far, and with which transport modes one can travel. In this context, it is also interesting to note that leisure travel is often seen as discretionary as opposed to, e.g., commuter trips, which are seen as more compulsory. In contrast, a study by Beck and Hensher [9] showed that when travel slowly returned after lockdown due to COVID-19, the effect was greater for nonwork trips that were more than returning to normal. The authors suggest that, particularly for social and recreational activities, people were even making up for lost time when planning their trips for the upcoming week.

\section{Conclusions}

Our findings suggest that people can use a variety of adaptive travel behaviors in the case of a disruptive event. When needed, people have been creative and have found new ways to travel to and participate in activities, especially regarding activities that are less fixed in time and space. As suggested by Marsden et al. [4], there is greater potential for societal adaptation if we can explain why it is necessary and what the benefits might be. In the case of the pandemic, the benefits of changing behaviors have been quite obvious. People have changed travel behavior due to restrictions, cancelled activities, to protect themselves, and out of consideration for others. However, even though the extent of the pandemic is rather long for being a disruptive event, the changes have still been made for a limited period of time. People seem to have moderate expectations about long-term effects of the adaptations made during the pandemic. The return to more normal travel patterns for everyday leisure trips when the spread of the infection decreased, and restrictions were lifted, also indicate that it may be more difficult to make such adaptations over a longer period of time. This is a challenge when it comes to the transition to more sustainable travel behavior.

On the other hand, the pandemic has shown that people are willing to adjust behavior not only for the sake of their own health and wellbeing, but also for that of others. This knowledge can be used when formulating messages to motivate people to change, focusing such messages both on considerations with respect to sustainability and on health and wellbeing. Another aspect is that although cancellation has commonly been used as an adaptive behavior during the pandemic, it is not the most viable policy strategy to strive for, since travelling for leisure purposes is vital for people's wellbeing. This study has shown that people find it possible to do more activities from home, and that they can consider making fewer leisure trips, but that having the freedom to take such trips in a flexible way is very important. Still, the pandemic has demonstrated that substantive changes in travel behavior are possible to achieve, and that people find creative solutions when needed.

The results of this study are based on qualitative interviews, aiming to understand the variety of adaptive travel behaviors used to cope with COVID-19. Further research, this time with a quantitative approach, would be an important contribution both to confirm the results of our limited number of interviews, and to investigate if some adaptive behaviors are more commonly used than others, and in that case, to quantify such potential differences. Another next step is to further identify the trips and activities that are replaceable and focus policy measures on these trip purposes, offering people the chance to engage in desired future leisure activities, but in a sustainable way. 
Author Contributions: Conceptualization, E.S., L.W.H., L.S.R. and H.S.; methodology, E.S., L.W.H., L.S.R. and H.S.; formal analysis, E.S.; investigation, E.S.; writing-original draft preparation, E.S.; writing-review and editing, E.S., L.W.H., L.S.R. and H.S.; visualization, E.S.; funding acquisition, L.W.H. and L.S.R. All authors have read and agreed to the published version of the manuscript.

Funding: This research was funded by the Swedish Energy Agency, grant number 2018-006595.

Institutional Review Board Statement: Ethical review and approval were waived for this study, due to the research not fulfilling any of the conditions specified in the Swedish Act Concerning the Ethical Review of Research Involving Humans (2003:460).

Informed Consent Statement: Informed consent was obtained from all subjects involved in the study.

Data Availability Statement: The interview study upon which the results of this article are based is part of PhD work. Further articles will be published using the same data. Since the project is ongoing, data cannot be shared at the moment. After project completion, aggregated data will be available.

Acknowledgments: The authors would like to thank the interviewees who provided important insights into their reasoning about adaptive travel behaviors for everyday leisure trips.

Conflicts of Interest: The authors declare no conflict of interest. The funders had no role in the design of the study; in the collection, analyses, or interpretation of data; in the writing of the manuscript, or in the decision to publish the results.

\section{Appendix A}

Table A1. Information about the sociodemographic background of the interviewees.

\begin{tabular}{|c|c|c|c|c|c|c|}
\hline Participant & Gender & Age Group & Household Type & Children in Family & Residence & Occupation \\
\hline P01 & Female & $18-24$ & Cohabitation & Siblings & Gävle & Student \\
\hline P02 & Male & $25-44$ & Cohabitation & No children & Other urban & Student \\
\hline P03 & Female & $18-24$ & Cohabitation & Siblings & Gävle & Student \\
\hline P04 & Female & $25-44$ & Single household & No children & Gävle & Employee \\
\hline P05 & Female & $25-44$ & Cohabitation & 7-18 years & Gävle & Employee \\
\hline P06 & Female & $45-64$ & Cohabitation & Grandchildren & Rural & Employee \\
\hline P07 & Female & $18-24$ & Single household & No children & Gävle & Student \\
\hline P08 & Female & $45-64$ & Single household & No children & Other urban & Pensioner \\
\hline P09 & Male & $18-24$ & Cohabitation & Siblings & Gävle & Student \\
\hline P10 & Male & $45-64$ & Single household & No children & Gävle & Pensioner \\
\hline P11 & Male & $25-44$ & Cohabitation & No children & Gävle & Employee \\
\hline $\mathrm{P} 12$ & Male & $45-64$ & Cohabitation & No children & Gävle & Employee \\
\hline P13 & Male & $25-44$ & Single household & $0-6$ and $7-18$ years & Gävle & Employee \\
\hline P14 & Male & $45-64$ & Cohabitation & $7-18$ years & Rural & Employee \\
\hline P15 & Male & $45-64$ & Cohabitation & Grandchildren & Gävle & Employee \\
\hline P16 & Male & $25-44$ & Cohabitation & $0-6$ and $7-18$ years & Other urban & Employee \\
\hline P17 & Female & $45-64$ & Cohabitation & $7-18$ years & Other urban & Employee \\
\hline
\end{tabular}

Table A2. Information about the interviewees' access to various transport modes.

\begin{tabular}{cccccc}
\hline Participant & $\begin{array}{c}\text { Driver's } \\
\text { License }\end{array}$ & Car Access & Bicycle Access & $\begin{array}{c}\text { Monthly } \\
\text { Ticket }\end{array}$ & $\begin{array}{c}\text { Distance } \\
\text { Bus Stop }\end{array}$ \\
\hline P01 & Studying & Gets a ride & Sometimes & $\begin{array}{c}\text { Sometimes } \\
\text { No }\end{array}$ & $200-399 \mathrm{~m}$ \\
P02 & Yes & 1 car & Sometimes & Sometimes & $200-399 \mathrm{~m}$ \\
P03 & No & 1 car & Always & No & $400-499 \mathrm{~m}$ \\
P04 & Yes & Shares a car & No & No & $400-999 \mathrm{~m}$ \\
P05 & Yes & 2 cars & More than one & No & $200-399 \mathrm{~m}$ \\
P06 & Yes & 1 car & Sometimes & No & $400-999 \mathrm{~m}$ \\
P07 & No & Gets a ride & Always & No & $200-399 \mathrm{~m}$ \\
P08 & Yes & Not now & No & Always & $200-399 \mathrm{~m}$ \\
P09 & No & 1 car & Always & No & $200-399 \mathrm{~m}$ \\
P10 & Yes & 1 car & Always & No & $200-399 \mathrm{~m}$ \\
P11 & Yes & 1 car & Always & &
\end{tabular}


Table A2. Cont.

\begin{tabular}{cccccc}
\hline Participant & $\begin{array}{c}\text { Driver's } \\
\text { License }\end{array}$ & Car Access & Bicycle Access & $\begin{array}{c}\text { Monthly } \\
\text { Ticket }\end{array}$ & $\begin{array}{c}\text { Distance } \\
\text { Bus Stop }\end{array}$ \\
\hline P12 & Yes & 1 car & More than one & No & $200-399 \mathrm{~m}$ \\
P13 & Revoked & Not now & Always & Sometimes & $200-399 \mathrm{~m}$ \\
P14 & Yes & 2 cars & Always & No & $\geq 1000 \mathrm{~m}$ \\
P15 & Yes & 2 cars & More than one & Now known & $200-399 \mathrm{~m}$ \\
P16 & Yes & 2 cars & Always & No & $\geq 1000 \mathrm{~m}$ \\
P17 & Yes & 2 cars & Always & No & $400-999 \mathrm{~m}$ \\
\hline
\end{tabular}

\section{References}

1. Weman Josefsson, K. Perspectives of life in Sweden during the COVID-19 pandemic. J. Clin. Sport Psychol. 2021, 15, 80-86. [CrossRef]

2. Witten, K.; Huakau, J.; Mavoa, S. Social and recreational travel: The destinations, travel modes and $\mathrm{CO}_{2}$ emissions of New Zealand households. Soc. Policy J. New Zealand 2011, 37, 172-184.

3. Harms, L. Overwegend Onderweg: De Leefsituatie en de Mobiliteit van Nederlanders; Sociaal en Cultureel Planbureau: Den Haag, The Netherlands, 2008.

4. Marsden, G.; Anable, J.; Chatterton, T.; Docherty, I.; Faulconbridge, J.; Murray, L.; Roby, H.; Shires, J. Studying disruptive events: Innovations in behaviour, opportunities for lower carbon transport policy? Transp. Policy 2020, 94, 89-101. [CrossRef]

5. Zhu, S.; Levinson, D.M. A Review of Research on Planned and Unplanned Disruptions to Transportation Networks. In Proceedings of the 89th Annual Transportation Research Board Meeting, Washington, DC, USA, 10-14 January 2010.

6. van Exel, N.J.A.; Rietveld, P. When strike comes to town... anticipated and actual behavioural reactions to a one-day, preannounced, complete rail strike in the Netherlands. Transp. Res. Part A Policy Pract. 2009, 43, 526-535. [CrossRef]

7. Anke, J.; Francke, A.; Schaefer, L.M.; Petzoldt, T. Impact of SARS-CoV-2 on the mobility behaviour in Germany. Eur. Transp. Res. Rev. 2021, 13, 10. [CrossRef]

8. Molloy, J.; Schatzmann, T.; Schoeman, B.; Tchervenkov, C.; Hintermann, B.; Axhausen, K.W. Observed impacts of the Covid-19 first wave on travel behaviour in Switzerland based on a large GPS panel. Transp. Policy 2021, 104, 43-51. [CrossRef]

9. Beck, M.J.; Hensher, D.A. Insights into the impact of COVID-19 on household travel and activities in Australia-The early days of easing restrictions. Transp. Policy 2020, 99, 95-119. [CrossRef] [PubMed]

10. de Haas, M.; Faber, R.; Hamersma, M. How COVID-19 and the Dutch 'intelligent lockdown' change activities, work and travel behaviour: Evidence from longitudinal data in the Netherlands. Transp. Res. Interdiscip. Perspect. 2020, 6, 100150. [CrossRef]

11. Vitrano, C. COVID-19 and Public Transport. A Review of the International Academic Literature; Media-Tryck: Lund, Sweden, 2021. Available online: https://www.k2centrum.se/sites/default/files/fields/field_uppladdad_rapport/covid-19_and_public_ transport.pdf (accessed on 9 November 2021).

12. Tirachini, A.; Cats, O. COVID-19 and public transportation: Current assessment, prospects, and research needs. J. Public Transp. 2020, 22, 1-34. [CrossRef]

13. Jenelius, E.; Cebecauer, M. Impacts of COVID-19 on public transport ridership in Sweden: Analysis of ticket validations, sales and passenger counts. Transp. Res. Interdiscip. Perspect. 2020, 8, 100242. [CrossRef]

14. Bryan, M.S.; Sun, J.; Jagai, J.; Horton, D.E.; Montgomery, A.; Sargis, R.; Argos, M. Coronavirus disease 2019 (COVID-19) mortality and neighborhood characteristics in Chicago. Ann. Epidemiol. 2021, 56, 47-54.e5. [CrossRef]

15. Cartenì, A.; Di Francesco, L.; Henke, I.; Marino, T.V.; Falanga, A. The role of public transport during the second COVID-19 wave in Italy. Sustainability 2021, 13, 11905. [CrossRef]

16. Hörcher, D.; Singh, R.; Graham, D.J. Social distancing in public transport: Mobilising new technologies for demand management under the Covid-19 crisis. Transportation 2021. [CrossRef] [PubMed]

17. Winslott Hiselius, L.; Arnfalk, P. When the impossible becomes possible: COVID-19's impact on work and travel patterns in Swedish public agencies. Eur. Transp. Res. Rev. 2021, 13, 17. [CrossRef]

18. Bohman, H.; Ryan, J.; Stjernborg, V.; Nilsson, D. A study of changes in everyday mobility during the Covid-19 pandemic: As perceived by people living in Malmö, Sweden. Transp. Policy 2021, 106, 109-119. [CrossRef]

19. Kolarova, V.; Eisenmann, C.; Nobis, C.; Winkler, C.; Lenz, B. Analysing the impact of the COVID-19 outbreak on everyday travel behaviour in Germany and potential implications for future travel patterns. Eur. Transp. Res. Rev. 2021, 13, 27. [CrossRef]

20. Zhang, J.; Hayashi, Y.; Frank, L.D. COVID-19 and transport: Findings from a world-wide expert survey. Transp. Policy 2021, 103, 68-85. [CrossRef] [PubMed]

21. Marsden, G.; Docherty, I. Mega-disruptions and policy change: Lessons from the mobility sector in response to the Covid-19 pandemic in the UK. Transp. Policy 2021, 110, 86-97. [CrossRef]

22. Schmidt, K.; Sieverding, T.; Wallis, H.; Matthies, E. COVID-19-A window of opportunity for the transition toward sustainable mobility? Transp. Res. Interdiscip. Perspect. 2021, 10, 100374. [CrossRef] 
23. How Might Personal Transportation Behaviors Change as a Result of COVID-19, and What Does That Mean for Policy? Available online: https:/ / www.enotrans.org/article/how-might-personal-transportation-behaviors-change-as-a-result-of-covid-19-andwhat-does-that-mean-for-policy/ (accessed on 17 June 2021).

24. COVID-19: The Questions Ahead for Future Travel and Transport. Available online: https://www.rand.org/blog/2020/04/ covid-19-the-questions-ahead-for-future-travel-and.html (accessed on 17 June 2021).

25. Loa, P.; Hossain, S.; Mashrur, S.M.; Liu, Y.; Wang, K.; Ong, F.; Habib, K.N. Exploring the impacts of the COVID-19 pandemic on modality profiles for non-mandatory trips in the Greater Toronto Area. Transp. Policy 2021, 110, 71-85. [CrossRef]

26. Bhaduri, E.; Manoj, B.S.; Wadud, Z.; Goswami, A.K.; Choudhury, C.F. Modelling the effects of COVID-19 on travel mode choice behaviour in India. Transp. Res. Interdiscip. Perspect. 2020, 8, 100273. [CrossRef]

27. Parkes, S.D.; Jopson, A.; Marsden, G. Understanding travel behaviour change during mega-events: Lessons from the London 2012 Games. Transp. Res. Part A Policy Pract. 2016, 92, 104-119. [CrossRef]

28. Adelé, S.; Tréfond-Alexandre, S.; Dionisio, C.; Hoyau, P.A. Exploring the behavior of suburban train users in the event of disruptions. Transp. Res. Part F Traffic Psychol. Behav. 2019, 65, 344-362. [CrossRef]

29. Nguyen-Phuoc, D.Q.; Currie, G.; De Gruyter, C.; Young, W. Transit user reactions to major service withdrawal-A behavioural study. Transp. Policy 2018, 64, 29-37. [CrossRef]

30. Guiver, J.; Jain, J. Grounded: Impacts of and Insights from the Volcanic Ash Cloud Disruption. Mobilities 2011, 6, 41-55. [CrossRef]

31. van Exel, N.J.; Rietveld, P. Public transport strikes and traveller behaviour. Transp. Policy 2001, 8, 237-246. [CrossRef]

32. Sadique, M.Z.; Edmunds, W.J.; Smith, R.D.; Meerding, W.J.; De Zwart, O.; Brug, J.; Beutels, P. Precautionary behavior in response to perceived threat of pandemic influenza. Emerg. Infect. Dis. 2007, 13, 1307-1313. [CrossRef]

33. Kim, C.; Cheon, S.H.; Choi, K.; Joh, C.-H.; Lee, H.-J. Exposure to fear: Changes in travel behavior during MERS outbreak in Seoul. KSCE J. Civ. Eng. 2017, 21, 2888-2895. [CrossRef]

34. Peak, C.M.; Wesolowski, A.; Erbach-Schoenberg, E.Z.; Tatem, A.J.; Wetter, E.; Lu, X.; Power, D.; Weidman-Grunewald, E.; Ramos, S.; Moritz, S.; et al. Population mobility reductions associated with travel restrictions during the Ebola epidemic in Sierra Leone: Use of mobile phone data. Int. J. Epidemiol. 2018, 47, 1562-1570. [CrossRef]

35. Aloi, A.; Alonso, B.; Benavente, J.; Cordera, R.; Echániz, E.; González, F.; Ladisa, C.; Lezama-Romanelli, R.; López-Parra, A.; Mazzei, V.; et al. Effects of the COVID-19 lockdown on urban mobility: Empirical evidence from the city of Santander (Spain). Sustainability 2020, 12, 3870. [CrossRef]

36. Beck, M.J.; Hensher, D.A. Insights into the impact of COVID-19 on household travel and activities in Australia-The early days under restrictions. Transp. Policy 2020, 96, 76-93. [CrossRef]

37. Falchetta, G.; Noussan, M. The Impact of COVID-19 on Transport Demand, Modal Choices, and Sectoral Energy Consumption in Europe; IEEE: Manhattan, NY, USA, 2020.

38. Šinko, S.; Prah, K.; Kramberger, T. Spatial modelling of modal shift due to covid-19. Sustainability 2021, 13, 7116. [CrossRef]

39. Eisenmann, C.; Nobis, C.; Kolarova, V.; Lenz, B.; Winkler, C. Transport mode use during the COVID-19 lockdown period in Germany: The car became more important, public transport lost ground. Transp. Policy 2021, 103, 60-67. [CrossRef]

40. König, A.; Dreßler, A. A mixed-methods analysis of mobility behavior changes in the COVID-19 era in a rural case study. Eur. Transp. Res. Rev. 2021, 13, 15. [CrossRef]

41. Bin, E.; Andruetto, C.; Susilo, Y.; Pernestål, A. The trade-off behaviours between virtual and physical activities during the first wave of the COVID-19 pandemic period. Eur. Transp. Res. Rev. 2021, 13, 14. [CrossRef]

42. Population in Sweden 31 December 2020 Municipal Comparative Figures. Available online: https://scb.se/en/finding-statistics/ statistics-by-subject-area/population/population-composition/population-statistics (accessed on 14 May 2021).

43. Population by Level of Education, Municipality and Sex, 2020. Available online: https://www.scb.se/en/finding-statistics/ statistics-by-subject-area/education-and-research/education-of-the-population/educational-attainment-of-the-population (accessed on 14 May 2021).

44. Vehicles in Counties and Municipalities at the Turn of Year 2020/2021. Available online: https://www.scb.se/en/findingstatistics/statistics-by-subject-area/transport-and-communications/road-traffic/registered-vehicles (accessed on 14 May 2021).

45. Cykelfrämjandet. Rapport för Gävle Kommun. Fördjupning av Cykelfrämjandets Kommunvelometer 2020. 2020. Available online: https: / / cykelframjandet.se/wp-content/uploads/2020/05/gavle-kommun-kommunrapport-kommunvelometern-20 20.pdf (accessed on 14 May 2021).

46. Linjekarta Stadstrafiken Gävle. Available online: https:/ /xtrafik.se/Content/126443/Gavle-stadslinjer-fran-17-aug-2020.pdf (accessed on 14 May 2021).

47. Trivector. Resvanor i Gävle Kommun 2018. Kartläggning Med Hjälp av ny Datainsamlingsmetod; Rapport 2019:05; Trivector Traffic: Lund, Sweden, 2019.

48. Bekräftade Fall i Sverige-Daglig Uppdatering. Available online: https://www.folkhalsomyndigheten.se/smittskyddberedskap/utbrott/aktuella-utbrott/covid-19/statistik-och-analyser/bekraftade-fall-i-sverige (accessed on 18 May 2021).

49. Beslut om Skärpta Allmänna råd i Gävleborgs-Och Västernorrlands Län. Available online: https:/ /www.folkhalsomyndigheten. se/nyheter-och-press/nyhetsarkiv/2020/november/beslut-om-skarpta-allmanna-rad-i-gavleborgs--och-vasternorrlands-lan (accessed on 18 May 2021).

50. Holden, E.; Linnerud, K. Troublesome leisure travel: Counterproductive sustainable transport policies. In Handbook on Transport and Development; Edward Elgar Publishing: Cheltenham, UK, 2015; pp. 587-598. 
51. Holden, E.; Linnerud, K. Troublesome leisure travel: The contradictions of three sustainable transport policies. Urban Stud. 2011, 48, 3087-3106. [CrossRef]

52. Kvale, S.; Brinkmann, S. InterViews: Learning the Craft of Qualitative Research Interviewing, 2nd ed.; Sage Publications: Thousand Oaks, CA, USA, 2009.

53. DeJonckheere, M.; Vaughn, L.M. Semistructured interviewing in primary care research: A balance of relationship and rigour. Fam. Med. Community Health 2019, 7, e000057. [CrossRef] [PubMed]

54. Braun, V.; Clarke, V. Using thematic analysis in psychology. Qual. Res. Psychol. 2006, 3, 77-101. [CrossRef] 